\title{
Pathogenic microbes contaminating mobile phones in hospital environment in Northeast India: incidence and antibiotic resistance
}

\author{
Christine Vanlalbiakdiki Sailo ${ }^{1}$, Puja Pandey ${ }^{1}$, Subhajit Mukherjee ${ }^{1}$, Zothan Zami ${ }^{1}$, Ralte Lalremruata ${ }^{2}$,
} Lalnun Nemi ${ }^{3}$ and Nachimuthu Senthil Kumar ${ }^{1 *}$ (D)

\begin{abstract}
Background: The present study attempts to identify and determine the pattern of drug susceptibility of the microorganisms present in mobile phones of health care workers (HCWs) and non-HCWs in a hospital environment. Mobile phones of 100 participants including both genders were randomly swabbed from nine different wards/units and the bacterial cultures were characterized using VITEK 2 system.

Results: Forty-seven mobile phones were culture positive and a total of 57 isolates were obtained which consisted of $28 \mathrm{Gram}$-positive organisms and $29 \mathrm{Gram}$-negative organisms. The predominating organisms were Acinetobacter baumannii and Staphylococcus hominis. Among all the isolates from the mobile phones of HCW and non-HCWs, five isolates had ESBL and three isolates had colistin resistance. Incidentally, MRSA was not found on the mobile phones tested. The isolated organisms showed $100 \%$ susceptibility to linezolid, daptomycin, vancomycin, imipenem, meropenem, gentamicin, amikacin, ciprofloxacin and tigecycline, while high resistance was shown against benzylpenicillin (75.0\%), cefuroxime and cefuroxime axetil (56.5\%). Non-HCWs' mobile phones were more contaminated as compared to HCWs $(P=0.001)$ and irrespective of individuals' gender or toilet habits, both Gram-positive and Gram-negative organisms were present on the mobile phones.

Conclusion: This study reports for the first time that the mobile phones of non-health care workers harbour more bacterial diversity and are more prone to cause transmission of pathogens. This study can serve to educate the public on personal hand hygiene practices and on maintaining clean mobile phones through antiseptic measures.
\end{abstract}

Keywords: Mobile phones, Microorganisms, Acinetobacter, Toilet, Healthcare workers, VITEK 2, Mizoram

\section{Background}

Mobile phones have become one of the most essential accessories of day-to-day life with recent advances in information sharing and social media applications [1]. The mobile phones contaminated with nosocomial pathogens is a potential mechanical vector for transferring pathogens with multidrug-resistant bacteria, especially extended-spectrum beta-lactamase (ESBL) across various wards in hospital settings [2]. During our daily activities,

\footnotetext{
* Correspondence: nskmzu@gmail.com

${ }^{1}$ Department of Biotechnology, Mizoram University, Aizawl, Mizoram 796004, India

Full list of author information is available at the end of the article
}

our hands come in contact with many surfaces containing germs and parallelly handle the phone. Over the course of time, these germs gradually accumulate on our phones and thus, phone and hand hygiene play a very crucial role in our health system. Most of the diseasecausing bacteria are transferred from person to person through direct contact and fomites [3].

This study was conducted in Mizoram, which is a landlocked state situated in the north-east of India, with unique lifestyle and food habits. The people of this state are known for their regular consumption of boiled and fermented foods and there are strong evidences of the impact of fermented foods on the digestive health such

(c) The Author(s). 2019 Open Access This article is distributed under the terms of the Creative Commons Attribution 4.0 International License (http://creativecommons.org/licenses/by/4.0/), which permits unrestricted use, distribution, and 
as dysbiosis and well-being [4]. The effects of certain lifestyle and food habits influence the gut microbiota which in turn can inhabit the mobile phones of their owners [5]. This study aims to survey the diversity of culturable microorganisms present on mobile phones which can vary owing to differences in hand flora, diet, occupation, habits and health awareness.

The key questions addressed in this study are as follows: (1) What is the contamination rate of mobile phones in a hospital environment and what are the predominant pathogens present? (2) Which are the most resistant microorganisms and what are their antibiotic resistance profiles? (3) What are the most important factors responsible for mobile contamination? In this study, identification and pattern of drug susceptibility of microorganisms isolated from mobile phones of both health care workers (HCWs) and non-health care workers (non-HCWs) in a hospital environment was carried out.

\section{Results}

Of the total 100 mobile phones swabbed, 47 samples showed positive growth (47\%)-from which 57 bacterial isolates were identified (28 Gram-positive organisms and 29 Gram-negative bacilli). Twenty-one mobile phones (44.7\%) were culture positive for Gram-positive organisms alone (including single and multiple organisms), while 23 mobile phones (48.9\%) were culture positive for Gram-negative bacilli (GNB) alone (including single and multiple organisms) and 3 mobile phones (6.4\%) had mixed growth of both Gram-positive and negative organisms (Tables 3 and 4).

\section{Antimicrobial susceptibility testing (AST)}

The AST of Gram-positive cocci (GPC) and GNB from both HCWs and non-HCWs are shown in Tables 3 and 4. Among the GNBs, out of five ESBL isolates (sample code MP-25, MP-26, MP-71, MP-80, MP-92), four were Enterobacter cloacae (one patient attendant from the Gynaecology ward, two patient attendants from the Medical ward and one patient from the Orthopaedic ward) and one was E. coli (female ward attendant from the Surgical ward). It is noteworthy that in the total three E. coli strains isolated, two were non-ESBL (sample code MP-60, MP-82) from non-HCWs belonging to the Gynaecology ward and Surgical ward, while one ESBL strain (sample code MP-80) was from HCW of the Surgical ward. We also identified two strains of Klebsiella pneumoniae which were nonESBL producers (Table 3).

Among the GNB, colistin resistance was shown by three isolates-E. coli (HCW, Surgical ward, sample code MP-80), Moraxella group and S. paucimobilis (non-HCWs, Gynaecology ward, sample codes MP-67 and MP-70). Intermediate drug resistance was shown by the Moraxella group against ceftriaxone and ampicillin as well as by $S$. paucimobilis against cefuroxime axitel and cefepime. These organisms were isolated from non-HCWs belonging to the Gynaecology ward. In GPC, intermediate resistance was shown against erythromycin by S. cohnii (non-HCW, Medical ward) and $S$. xylosus (HCW, k-ward) and against teicoplanin by S. hominis (HCW, ENT ward). Of the 29 GNB isolated, six isolates (Pantoea spp., Oligella ureolytica, Klebsiella pneumoniae, Aeromonas salmonicida, and two strains of Acinetobacter lwoffii) could not produce AST results when tested by VITEK 2 and therefore are not included in AST.

In this study, we observed that the most resistant GNB was Enterobacter cloacae (ESBL) isolated from non$\mathrm{HCW}$ belonging to the Medical ward (sample code MP26). This isolate showed resistance to 10 antibiotics $(55.55 \%)$ out of the 18 antibiotics tested. On the contrary, the most susceptible GNB was Sphingomonas paucimobilis isolated from a $\mathrm{HCW}$ belonging to Microbiology laboratory (sample code MP-4). This isolate showed susceptibility to all the 18 antibiotics tested $(100 \%)$ (Table 3). Conversely, the most resistant GPC was $S$. haemolyticus isolated from non-HCW belonging to the Medical ward (sample code MP-23). This isolate showed resistance to 10 antibiotics (62.5\%) out of the 16 antibiotics tested. The most susceptible (100\%) Grampositive cocci were S. sciuri (isolated from HCW, ENT ward, sample code MP-39), S. warneri (isolated from non-HCW, ENT ward, sample code MP-31) and $S$. hominis (isolated from non-HCW, Gynae ward, sample code MP-69). These isolates showed susceptibility against all the antibiotics tested (Table 4).

Among the GPC, there were eight isolates of coagulasenegative Staphylococcus (CoNS) that had shown resistance to beta-lactams as well as modification of penicillinbinding protein (mecA). These included four strains of $S$. haemolyticus (sample codes MP-23, MP-24, MP-29, MP$35)$ which were from non-HCWs (Medical ward and ENT ward), three strains of S. hominis (sample codes MP-39, MP-47, MP-72) which were from HCWs (ENT ward) and non-HCWs (Gynaecology ward) and one S. epidermidis (sample code MP-85) from non-HCW (Surgical ward).

\section{Single/multiple and mixed growth with respect to wards/ units}

Eight wards/units had either single/multiple and/or mixed growth of both Gram-positive and Gram-negative organisms. Interestingly, in the Orthopaedic ward, all the isolates obtained were GNBs. Mobile phones swabbed from ENT (72.7\%) and Gynaecology (56.2\%) wards were more contaminated as compared with other wards/units (Table 1).

\section{Bacterial isolates from mobile phones in relation to different parameters}

An informed verbal consent was obtained and a set of questionnaire was asked to all the participants pertaining 
Table 1 Bacterial growth from mobile phones belonging to different wards/units

\begin{tabular}{|c|c|c|c|c|c|c|}
\hline \multirow[t]{2}{*}{ Wards/units } & \multirow{2}{*}{$\begin{array}{l}\text { No. of } \\
\text { samples }\end{array}$} & \multirow{2}{*}{$\begin{array}{l}\text { No. of } \\
\text { growth } \\
\text { (\%) }\end{array}$} & \multicolumn{3}{|c|}{ Total no. } & \multirow[t]{2}{*}{ Organisms isolated } \\
\hline & & & Isolates & GNB's & GPC's/GPB & \\
\hline Microbiology unit & 05 & $02(40.00)$ & 02 & 01 & 01 & 1 Sphingomonas paucimobilis, 1 Staphylococcus aureus (MSSA) \\
\hline Blood bank unit & 04 & $01(25.00)$ & 01 & 00 & 01 & 1 Staphylococcus cohnii \\
\hline Pathology unit & 09 & $01(11.11)$ & 01 & 00 & 01 & 1 Staphylococcus arlettae \\
\hline Medical ward & 11 & $06(54.54)$ & 07 & 02 & 05 & $\begin{array}{l}3 \text { Staphylococcus hemolyticus, } 2 \text { Enterobacter cloacae, } 1 \text { Staphylococcus } \\
\text { cohnii and } 1 \text { Alloiococcus otitis }\end{array}$ \\
\hline ENT ward & 11 & $08(72.72)$ & 13 & 03 & 10 & $\begin{array}{l}2 \text { Staphylococcus warneri, } 2 \text { Staphylococcus hominis, } 1 \text { Staphylococcus } \\
\text { epidermidis, } 2 \text { Staphylococcus saprophyticus, } 1 \text { Acinetobacter Iwoffii, } \\
1 \text { Pantoea spp., } 1 \text { Kocuria kristinae, } 1 \text { Acinetobacter hemolyticus, } \\
1 \text { Staphylococcus sciuri and } 1 \text { Staphylococcus hemolyticus }\end{array}$ \\
\hline K ward & 04 & $01(25.00)$ & 01 & 00 & 01 & 1 Staphylococcus xylosus \\
\hline Gynaecology ward & 32 & $18(56.25)$ & 20 & 13 & 07 & $\begin{array}{l}4 \text { Acinetobacter baumanii, } 1 \text { Enterobacter cloacae, } 4 \text { Staphylococcus } \\
\text { hominis, } 2 \text { Acinetobacter Iwoffii, } 2 \text { Moraxella group, } 1 \text { Sphingomonas } \\
\text { paucimobilis, } 1 \text { Staphylococcus aureus, } 1 \text { Pantoea spp., } 1 \text { Staphylococcus } \\
\text { epidermidis, } 1 \text { Klebsiella pneumoniae, } 1 \text { Erysipelothrix rhushiopathiae } \\
\text { and } 1 \text { E.coli }\end{array}$ \\
\hline Surgical ward & 15 & 05 (33.33) & 07 & 05 & 02 & $\begin{array}{l}2 \text { Escheriachia coli, } 1 \text { Acinetobacter baumanii, } 1 \text { Staphylococcus } \\
\text { epidermidis, } 1 \text { Klebsiella pneumoniae, } 1 \text { Enterococcus spp. and } \\
1 \text { Oligella ureolytica }\end{array}$ \\
\hline Orthopaedic ward & 09 & $05(55.55)$ & 05 & 05 & 00 & $\begin{array}{l}2 \text { Acinetobacter Iwoffii, } 1 \text { Acinetobacter baumanii, } 1 \text { Enterobacter } \\
\text { cloacae and } 1 \text { Aeromonas salmonicida }\end{array}$ \\
\hline
\end{tabular}

GNB Gram-negative bacilli, GPC Gram-positive cocci

$K$ ward substance abuse ward, ENT ear, nose and throat ward

to gender, occupation [HCWs, non-HCWs (patients and patient attendants), their associated hospital wards/units, habit of cleaning their mobile phones and of carrying their phones to toilet (Table 2).

Out of 100 participants, 32 were males and 15 (46.9\%) of their mobile phones were culture positive, whereas 68 were females and $30(44.1 \%)$ of their mobile phones were culture positive ( $p$ value $=0.680 ; \mathrm{OR}=1.194 ; \mathrm{CI}=0.515-$ $2.769)$. With respect to occupation, out of the 100 participants, 66 were non-HCWs and 34 were HCWs. The bacterial contamination rate of mobile phones among the non-HCWs was $59.1 \%$ and HCWs was $23.5 \%$. We observed that non-HCWs mobile phones had more contamination $(p=0.001 ; \mathrm{OR}=4.694 ; \mathrm{CI}=1.848-11.922)$ as compared to HCWs (Table 2). With respect to occupation, the type of organisms isolated revealed that non-HCWs phones were more contaminated with Acinetobacter baumannii $(n=5)$ and Acinetobacter lwoffii $(n=$ $5)$. On the contrary, there were no predominating organisms in the mobile phones of HCWs (Figs. 1 and 2).

With respect to the cleanliness of mobile phones, 23 participants had cleaned (without antiseptics) and 77 participants never cleaned their mobile phones (Table 2). Among these 23 participants, 10 samples were culture positive (43.4\%) and maximum growth was contributed by Enterobacter cloacae, Acinetobacter lwoffii and $S$. hominis. The remaining were Sphingomonas paucimobilis, S. cohnii, S. haemolyticus, S. warneri, Acinetobacter baumannii, Moraxella group, S. aureus (MSSA) and A. haemolyticus (Fig. 3).

From the 77 uncleaned mobile phones, a total of 24 organisms were isolated (31.16\%) (Table 2). Acinetobacter baumannii was abundant, followed by $S$. hominis, $S$. haemolyticus, Acinetobacter lwoffii, S. epidermidis and E. coli. Apart from the common organisms that grew both in the cleaned and uncleaned mobile phones, the uncleaned phones had additional growth of organisms such as Klebsiella pneunoniae, S. epidermidis, S. saprophyticus, S. arlettae, S. sciuri, S. xylosus, Enterococcus spp., Alloiococcus otitis, Kocuria kristinae, Pantoea spp., E. coli, Erysipelothrix rhusiopathiae, Oligella ureolytica and Aeromonas salmonicida (Fig. 3). The contamination rate was significantly higher in the uncleaned phones compared to the cleaned ones (statistical findings from Table 2).

Eighty-two (82) individuals used to carry their mobile phones inside the toilet, out of which 39 mobile phones (47.5\%) were culture positive yielding 46 isolates (Table 2). In total, these isolates contained 25 types of organisms with a dominance of S. hominis (Fig. 4). Nine (50\%) out of 18 mobile phones that were never carried inside the toilet were culture positive and from them, 11 isolates (containing 9 types of microbes) were identified with a dominance of Acinetobacter baumannii (Table 2, Fig. 4). There was no statistical significance in the number of microbial growth between the mobile phones that were and were not carried inside the toilet $(p=0.700)$ (Table 2). 
Table 2 Relationship between bacterial isolate numbers and different parameters

\begin{tabular}{|c|c|c|c|c|c|c|}
\hline \multicolumn{7}{|l|}{ No. of bacterial isolates } \\
\hline \multirow[t]{2}{*}{ Factors } & No growth & Growth per mobile phone ${ }^{a}$ & Total no. of isolates ${ }^{b}$ & \multirow[t]{2}{*}{$p$ value } & \multirow[t]{2}{*}{ OR } & \multirow[t]{2}{*}{$\mathrm{Cl}$} \\
\hline & No. (\%) & No. (\%) & No. (\%) & & & \\
\hline \multicolumn{7}{|l|}{ Gender } \\
\hline Male & $17(53.12)$ & $15(46.88)$ & $19(33.33)$ & 0.680 & 1.194 & $0.515-2.769$ \\
\hline Female & $38(55.88)$ & $30(44.12)$ & $38(66.67)$ & & & \\
\hline \multicolumn{7}{|l|}{ Occupation } \\
\hline $\mathrm{HCW}$ & $26(76.47)$ & $08(23.53)$ & $10(17.54)$ & 0.001 & 4.694 & $1.848-11.922$ \\
\hline Non-HCW & $27(40.90)$ & $39(59.10)$ & $47(82.46)$ & & & \\
\hline \multicolumn{7}{|l|}{ Mobile cleaning } \\
\hline Yes & $13(56.52)$ & $10(43.48)$ & $15(26.32)$ & Reference & 3.756 & $1.240-11.373$ \\
\hline Never & $39(50.65)$ & $38(49.35)$ & $42(73.68)$ & 0.019 & & \\
\hline \multicolumn{7}{|c|}{ Use of mobile in the toilet } \\
\hline Never & $09(50.00)$ & $09(50.00)$ & $11(19.30)$ & Reference & 1.202 & $0.471-3.072$ \\
\hline Yes & $43(52.44)$ & $39(47.56)$ & $46(80.70)$ & 0.700 & & \\
\hline \multicolumn{7}{|c|}{ Wards/Units } \\
\hline Surgical ward & $10(66.67)$ & $05(33.33)$ & $07(12.28)$ & Reference & & \\
\hline Pathology unit & 08 (88.89) & $01(11.11)$ & $01(1.75)$ & 0.246 & 0.250 & $0.024-2.594$ \\
\hline Microbiology unit & $03(60.00)$ & $02(40.00)$ & $02(3.51)$ & 0.787 & 1.333 & $0.165-10.743$ \\
\hline Blood bank unit & $03(75.00)$ & $01(25.00)$ & $01(1.75)$ & 0.751 & 0.667 & $0.054-8.161$ \\
\hline Medical ward & $05(45.45)$ & $06(54.55)$ & $07(12.28)$ & 0.284 & 2.400 & $0.484-11.891$ \\
\hline ENT ward & $03(27.27)$ & $08(72.73)$ & $13(22.81)$ & 0.055 & 5.333 & $0.968-29.393$ \\
\hline K ward & $03(75.00)$ & $01(25.00)$ & $01(1.75)$ & 0.751 & 0.667 & $0.054-8.161$ \\
\hline Gynaecology ward & $14(43.75)$ & $18(56.25)$ & $20(35.10)$ & 0.148 & 2.571 & $0.714-9.255$ \\
\hline Orthopaedic ward & $04(44.44)$ & $05(55.56)$ & 05 (8.77) & 0.290 & 2.500 & $0.458-13.649$ \\
\hline
\end{tabular}

References represent the variable against which the tested factors were compared

$\mathrm{OR}$ odds ratio, is a measure of association between an exposure and an outcome; $\mathrm{Cl}$ confidence interval, indicates a measurement precision. Narrow $\mathrm{Cl}$ indicates high precision; Wide $\mathrm{Cl}$ indicates low precision; $p$ value, the probability of finding the observed results when the null hypothesis is true (indicates significance $<$ $0.05)$; ENT ears, nose and throat; $K$ ward substance abuse ward

${ }^{a}$ Growth observed per individual's mobile phone

'Total no. of bacterial isolates from each individual's mobile phone (includes $>1$ organism per mobile phone)

\section{Discussion}

Nowadays, mobile phones are being owned and widely used everywhere by almost every individual irrespective of age, socio-economic status and educational level. It, therefore, has become an easy source of microorganism transmission. In the present study, $47 \%$ of the mobile phones were contaminated, whereas earlier studies had shown mobile phone contamination up to $94.5 \%$ and $30 \%[6,7]$. This variation could be attributed to knowledge of hand hygiene and sanitary practices and with rapid dissemination of awareness and precautions. This study proved that the mobile phones harbour both Gram-positive organisms ( $n=28$, i.e., $49.1 \%)$ and Gramnegative bacilli ( $n=29$, i.e., $50.9 \%$ ) irrespective of belonging to HCWs or non-HCWs. Though this figure is not significantly high, more number of GNB was isolated. This is not in agreement with other studies where
Gram-positive organisms (80\%) were abundant rather than Gram-negative organisms $(20 \%)[8,9]$.

For GNB, the antibiotic resistance and susceptibility pattern among microbes isolated from mobile phones were almost similar to other previous studies [10], except for ampicillin (34.78\%), piperacillin/tazobactam $(4.35 \%)$ and cefuroxime axetil (56.52\%) (Table 3). This low susceptibility to cefuroxime axetil can be attributed to the fact that it falls under the commercially available second generation of cephalosporins which were once widely used as therapy. Cefuroxime axetil was active against a wide range of organisms and its use decreased later due to the acquisition of resistance which led to the use of broader classes of cephalosporins like third, fourth and fifth generations [11].

In concordance with previous studies, GNB had 100\% susceptibility to imipenem, meropenem, amikacin and 


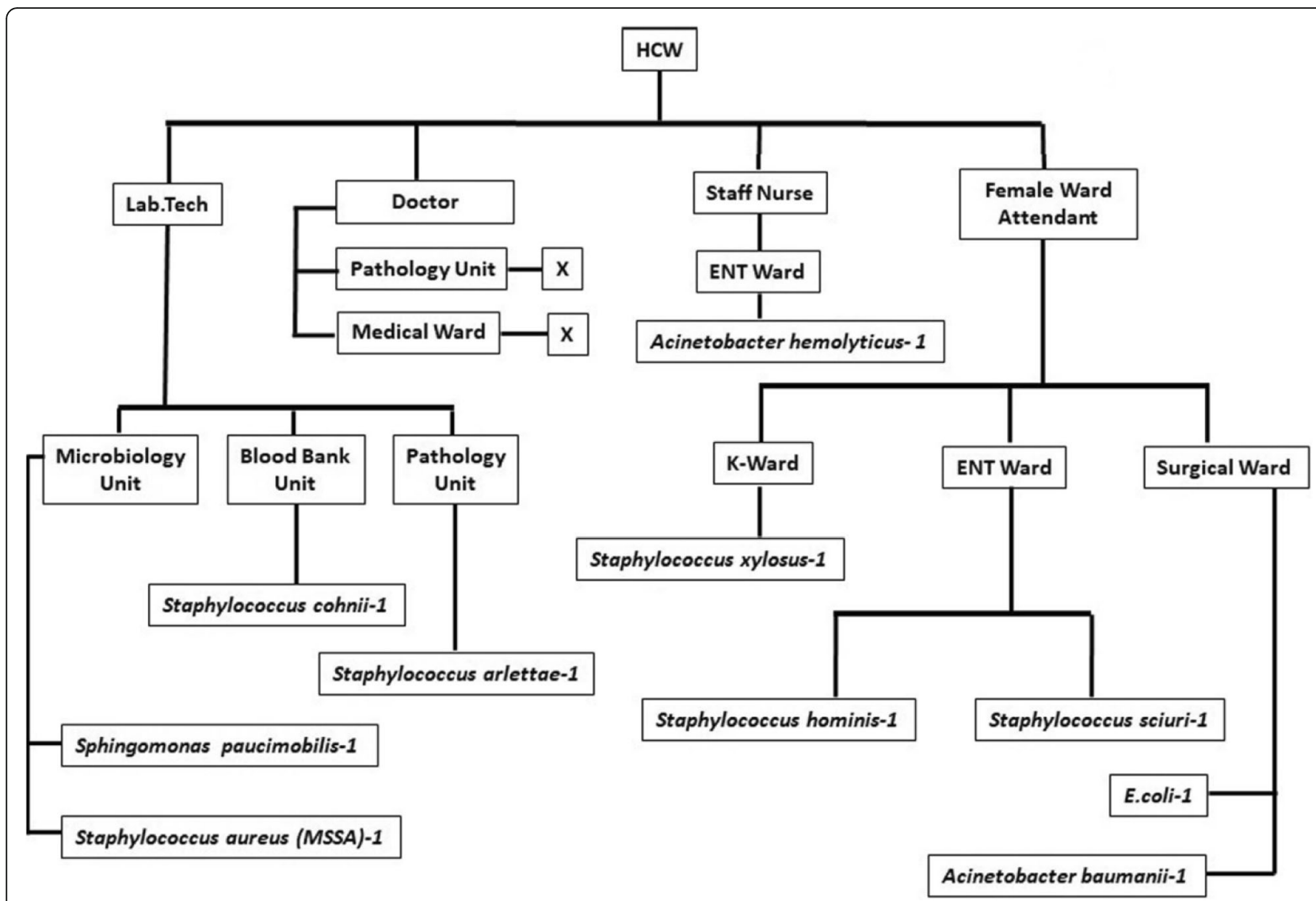

Fig. 1 Bacterial isolates obtained from health care workers in a hospital environment. K-ward, substance abuse ward. X, Nil microorganisms isolated

ciprofloxacin [12]. This can be attributed to the fact that the carbapenems such as imipenem and meropenem are reserved drugs which are seldom used, unless needed, and hence, GNB showed good susceptibility (100\%) towards those drugs. This is in accordance with other previous studies [13]. It is noteworthy to mention that mobile phones of patient attendants (non-HCWs) and female ward attendants (HCWs) harboured extremely important nosocomial pathogens which were extended spectrum beta-lactamase (ESBL) microorganisms such as Enterobacter cloacae and E. coli. Such individuals can act as a source of ESBL transmission from patient-topatient, patient-to-healthcare workers and patient/ward attendants to patients during hospitalization $[14,15]$. In our study, of the three isolated E. coli strains, two were non-ESBL producers and one was ESBL producer. In addition, two Klebsiella pneumoniae strains isolated from patient attendants of surgery and Gynae wards were non-ESBL producer. That E. coli and Klebsiella can be both ESBL producer and non-ESBL producer is supported by a previous study [16].

Three colistin resistance strains were identified among all the GNB isolates obtained. These are E.coli (HCW,
Surgical ward), S. paucimobilis and Moraxella group (non-HCWs, Gynaecology ward). However, only E. coli was flagged as polypeptides resistant by VITEK 2 system. Since colistin is a last resort drug and the associated resistance gene is transmissible to other drug naïve bacterial species as well as pathogens, carriage of the resistance gene to pathogens harbouring other resistance genes can give rise to super drug-resistant bacteria [17]. In this study, the presence of a colistin-resistant E. coli strain on a HCW signifies the alarming chances of it being transmitted across various wards which could eventually lead to a great hazard in clinical practice.

CoNS are well known opportunistic pathogens in hospital settings that result in high-end infections since they have the ability to adhere and invade epithelial cell lines, like HeLa [18] and form biofilms in prosthetic devices ultimately resulting in drug resistance $[19,20]$. In this study, overall, 28 Gram-positive isolates were identified of which 22 were contributed by CoNS. It is not clear to us as to what extent these CoNS would have infected patients from this hospital.

As an antibiotic, benzylpenicillin is noted to possess efficacy against a wide variety of infections [10]. In the 


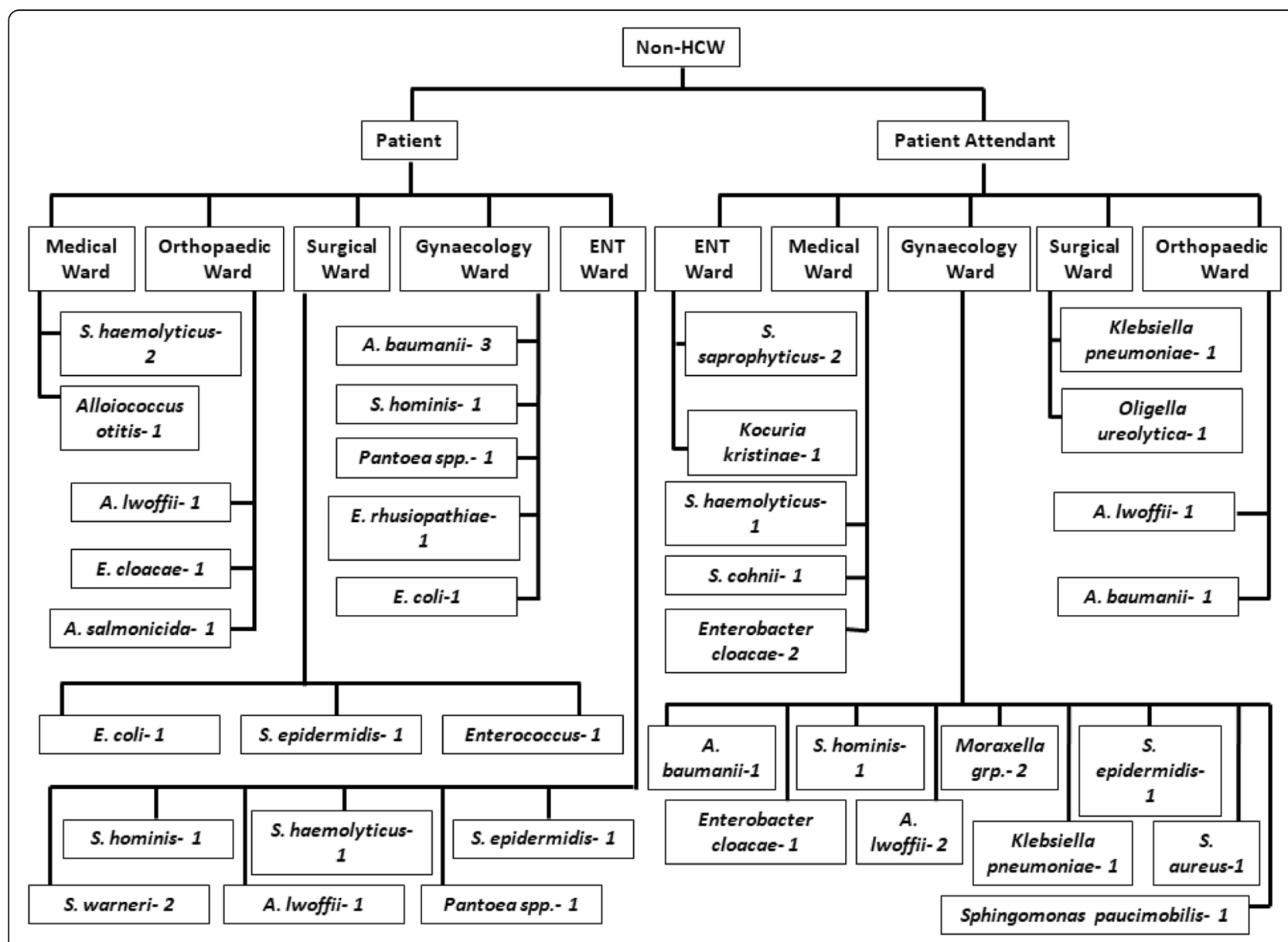

Fig. 2 Bacterial isolates obtained from non-health care workers in a hospital environment. 1, 2 and 3 represents the number of organisms isolated

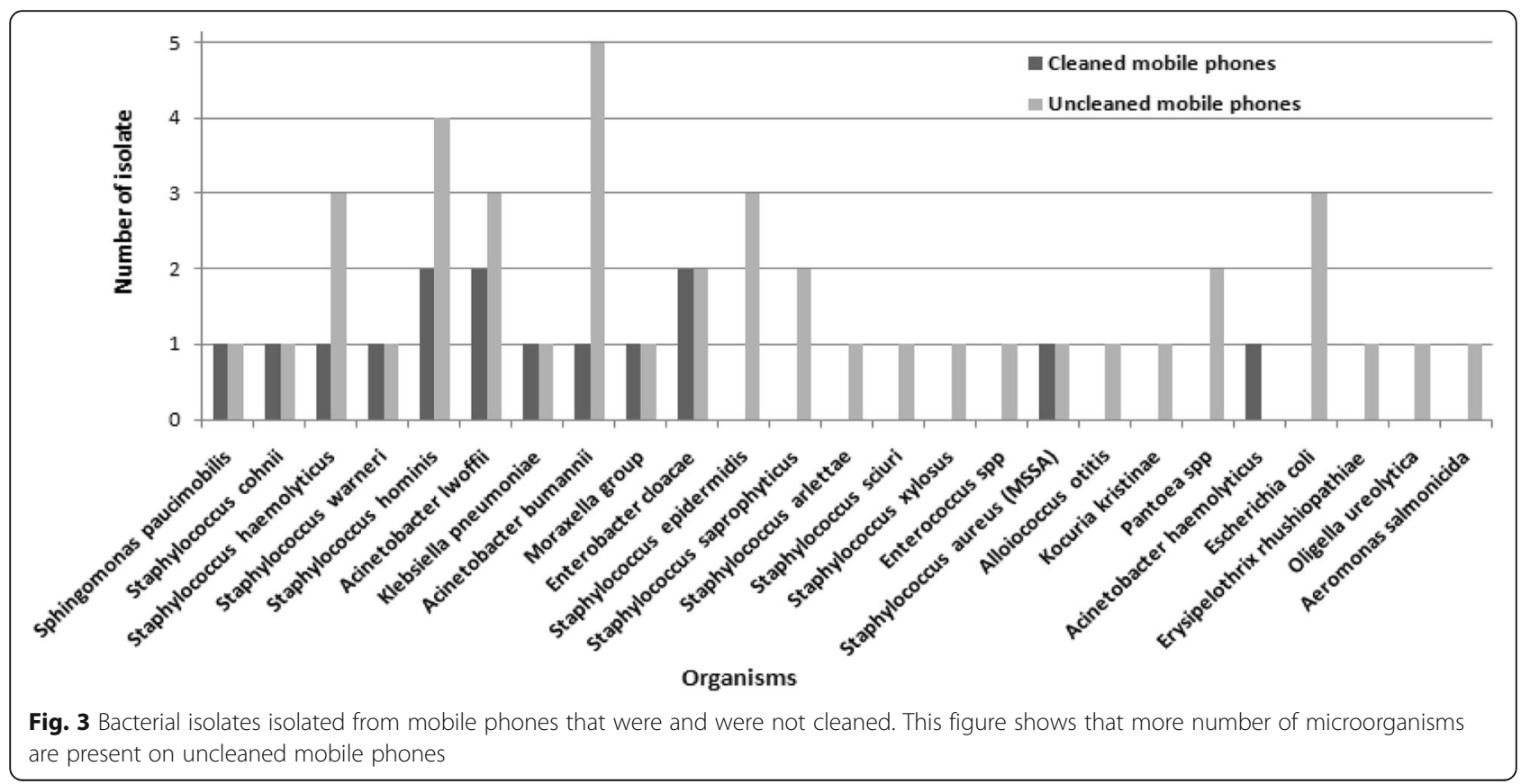




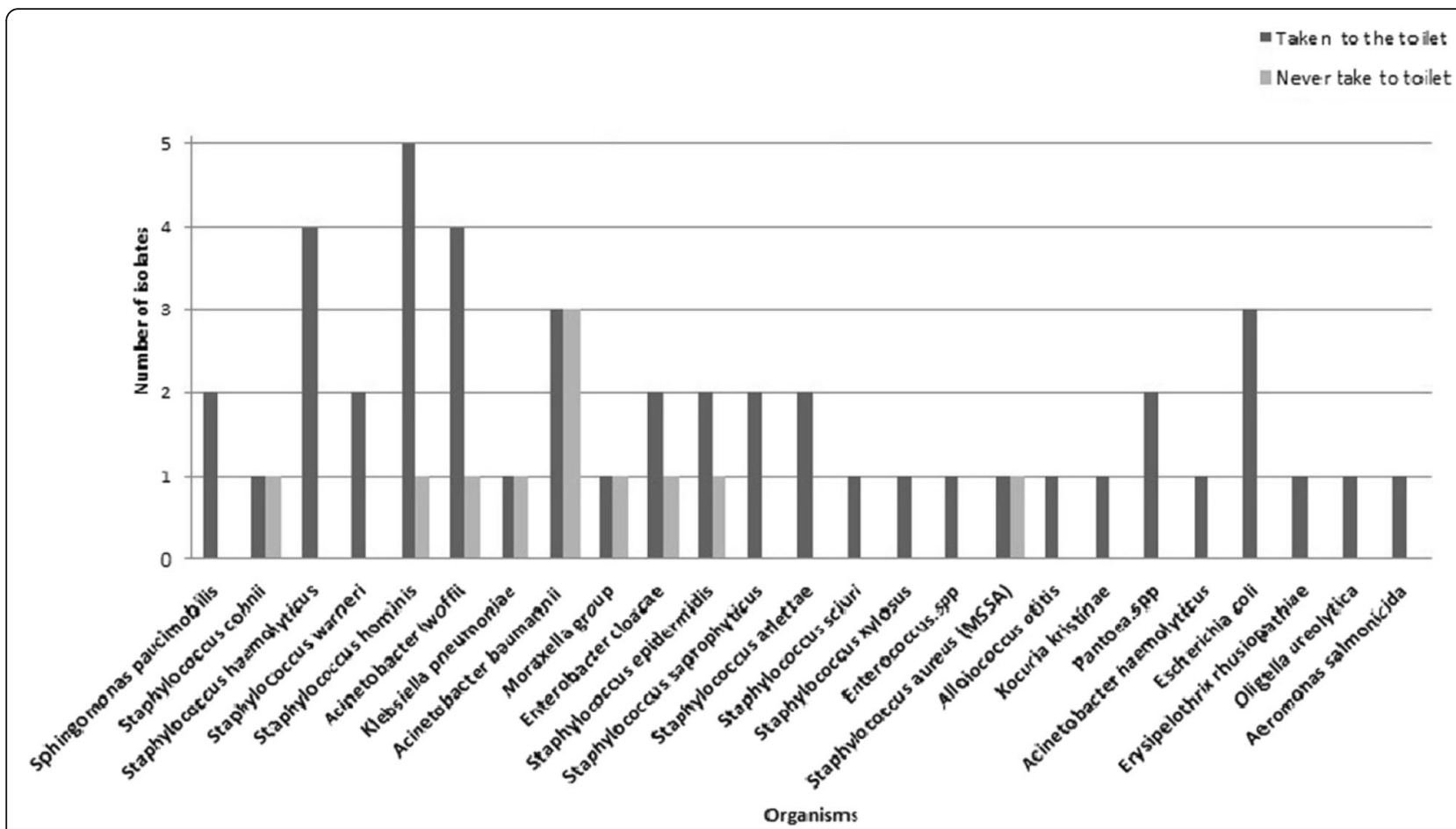

Fig. 4 Bacterial isolates from mobile phones that were and were not taken inside the toilet. This figure shows that more number of microorganisms are present on mobile phones that were taken inside the toilet

present study, the GPC had $75 \%$ resistance against benzylpenicillin, whereas it was found to be $100 \%$ in an earlier study [21]. This pattern of high resistance towards this antibiotic could be due to the rampant utilization of different groups of antibiotics including penicillin group of drugs, not only for empirical treatment but also for non-curative reasons like prophylaxis and metaphylaxis in animal feed stocks which thereby promotes drug resistance [22]. The GPC in our findings showed 100\% susceptibility towards linezolid, vancomycin and tigecycline which is in total agreement with previous finding [23]. This could be due to the fact that they fall under second line drugs which are seldom used unless needed and hence showed good susceptibility [12].

In this study, no significant gender association was found between the organisms isolated from mobile phones of both male and female participants. With respect to occupation, mobile phones of non-HCWs (patient and patient attendants) were significantly contaminated ( $p=$ 0.001 ) as compared to those of HCWs and were predominantly contaminated with $A$. baumannii and $A$. lwoffii. This can be attributed to the proper hand hygiene awareness and practices among the HCWs resulting in the constant sterilization of hands either by hand-washing or using sanitizer upon touching patients and hospital devices. Hence, hand hygiene is the leading measure for preventing the transmission of antimicrobial resistance and reducing healthcare-associated infections [24].
As anticipated in this study, mobile phones which were never cleaned had more microorganisms $(p=$ 0.019) and A. baumannii, S. hominis, A. lwoffii, S. haemolyticus, S. epidermidis and E. coli dominated other microorganisms (Fig. 3, Table 2). A similar finding was also reported by Koscova et al. [25] where the researchers also concluded that cleaning of mobile phones especially with antibacterial solutions can markedly reduce microbial contamination with an effective range of 36.8 to $100 \%$.

Previous studies have regarded toilets as a source of microbial contamination and a hidden source of microbial transmission of pathogens across various individuals [26]. We found more number of microorganisms on mobile phones that were carried inside the toilet, and among them, S. hominis predominated (Fig. 4). Various sub-species of this species had been implicated for nosocomial outbreaks causing bloodstream infections in patients with underlying malignancies [27].

Our sampling was carried out during summer and the genus Acinetobacter as such are part of the human skin flora which shows seasonal variability of $53 \%$ during summer vs $32 \%$ during winter [28, 29]. In this study, GNBs such as Acinetobacter lowffii, Acinetobacter baumannii and E. coli predominated in the mobile phones taken inside the toilet, and interestingly, an equal number of Acinetobacter baumannii was also found among those mobile phones that were never taken inside the 
Table 3 Antibiotic susceptibility and resistance pattern for GNB

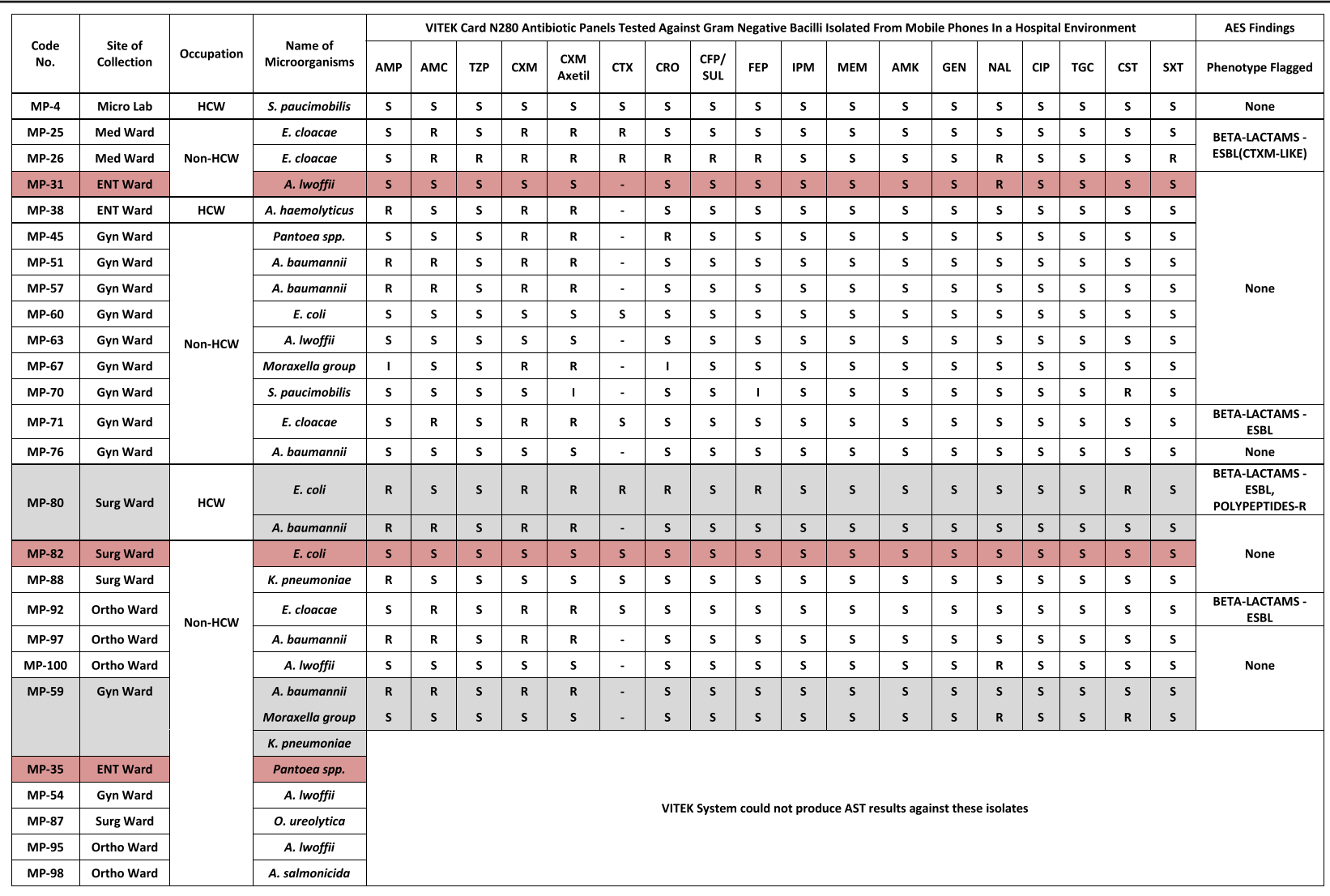

AMP ampicillin, $A M C$ amoxicillin/clavulanic acid, TZP piperacillin/tazobactam, CXM cefuroxime, CTX cefotaxime, CRO ceftriaxone, CFP/SUL cefoperazone/sulbactam, FEP cefepime, IPM imipenem, MEM meropenem, AMK amikacin, GEN gentamicin, NAL nalidixic acid, CIP ciprofloxacin, TGC tigecycline, CST solistin, SXT trimethoprim/sulfamethoxazole, $S$ susceptible, $R$ resistant

Grey highlight-mobile phones having growth of $>1$ organisms of the same Gram reaction

Pink highlight-mobile phones having mixed growth of both Gram-positive and Gram-negative organisms

toilet (Fig. 4). Acinetobacter baumannii has been reported to colonize the skin at very low levels and is an emerging multidrug-resistant pathogen in community and hospital environments which recognizes them as the most difficult GNB to control and treat [30-32]. Acinetobacter spp. have been reported to colonize up to $75 \%$ in hospitalized patients vs $43 \%$ of community dwellers and among these community dwellers, Acinetobacter lowffii contributed 58\% [33]. Other microorganisms such as S. cohnii, K. pneumoniae, Moraxella group and $S$. aureus (MSSA) were also found in equal percentage in both the groups in the present study (Fig. 4).

We also observed that in our study, most of the microorganisms tested against the panel of antibiotics were of susceptible strains, which indicates that these microorganisms might have come from the community through the patients, patient attendants and/or hospital staff. Over time, such microorganisms can acquire resistance and infect patients when the opportunity arises and can even be fatal. Organisms like S. aureus (MRSA), CoNS and ESBL are well known for bloodstream infections leading to septicaemia and death [34]. The main drawback of this study apart from sample size is that an equal number of sampling from different sources could not be carried out due to the unavailability of an equal number of patients at the time of sample collection.

\section{Conclusion}

From this study, the most important factor associated with mobile contamination was being unaware of the facts that mobile phones can harbour microorganisms and mobile phones need to be cleaned with antiseptics. The novel finding of our work is that the mobile phones of non-health care workers are more contaminated and are more prone to cause transmission of pathogens. This study can create public awareness regarding the danger of transmission of germs through mobile phones and can educate the people about hand hygiene practices and regular cleaning of mobile phones with antiseptics. 


\section{Materials and methods}

\section{Sample collection}

A total of 100 mobile phone swab samples were aseptically collected from a mission hospital using sterile cotton swab in screw-capped polypropylene tubes (HiMedia PW003-1x100NO) moistened with 9\% sterile normal saline. The entire surface of the phone including the screen, buttons of keypads, sides and back, mouth and ear piece, volume and lock keys and the cover inside out were thoroughly swabbed [35]. Participants were both HCWs and non-HCWs and were randomly selected as per their convenience at the time of sample collection during the Summer period (March-May 2018). Mobile phone swab samples were collected from nine locations (six wards and three units) within the hospital as follows: 18 samples from three laboratory units (Microbiology5, Blood bank-4 and Pathology unit-9) and 82 samples from six wards (Surgical ward-15, Medical ward-11, ENT ward-11, K-ward-4, Gynaecology ward-32, Orthopaedic ward-9) (Table 2). Further, the 82 samples were from patient attendants -37 , patients -29 , female ward attendants -4 , staff nurse -11 and ward doctor -1 and the 18 samples were from Lab technicians-17 and laboratory doctor-1.

\section{Sample processing and identification}

All samples were processed at the Microbiology laboratory in the mission hospital, Mizoram, by plating on sheep blood agar plate (HiMedia MP1301), MacConkey agar (HiMedia MH081) and chromogenic media (HiCHROME UTI Agar M1353) using the three-phase streaking pattern and incubating aerobically at $37^{\circ} \mathrm{C}$ for 24-36 h. Gram staining (HiMedia K001) was performed on isolated colonies and identified using VITEK 2 system (BioMérieux, Biotechnology Company; France). VITEK identification cards were selected as per the morphology and Gram reaction of the bacteria [36]. This automated system monitors the kinetics of bacterial growth, calculates it using a unique algorithm and follows a Clinical and Laboratory Standards Institute (CLSI) guidelines [37].

Table 4 Antibiotic susceptibility and resistance pattern for GPC/GPB

\begin{tabular}{|c|c|c|c|c|c|c|c|c|c|c|c|c|c|c|c|c|c|c|c|c|}
\hline \multirow{2}{*}{$\begin{array}{l}\text { Code } \\
\text { No. }\end{array}$} & \multirow{2}{*}{$\begin{array}{l}\text { Site of } \\
\text { Collection }\end{array}$} & \multirow{2}{*}{ Occupation } & \multirow{2}{*}{$\begin{array}{c}\text { Name of } \\
\text { Microorganisms }\end{array}$} & \multicolumn{16}{|c|}{ VITEK Card P628 Antibiotic Panels Tested Against GPC/GPB Isolated From Mobile Phones in a Hospital Environment } & \multirow{2}{*}{$\begin{array}{c}\text { AES Findings } \\
\text { Phenotype Flagged }\end{array}$} \\
\hline & & & & $\begin{array}{l}\text { FOX } \\
\text { Screen }\end{array}$ & $\begin{array}{c}\text { Banzyl } \\
\text { PEN }\end{array}$ & OXA & GEN & CIP & $\mathrm{NVX}$ & ERY & CLI & LZD & DAP & TEC & VAN & TET & TGC & RIF & SXT & \\
\hline MP-5 & Micro Lab & \multirow{3}{*}{ HCW } & S. aureus & NEG & $\mathbf{R}$ & $\mathbf{s}$ & $s$ & $\mathbf{R}$ & $\mathbf{R}$ & $\mathbf{R}$ & $s$ & $s$ & $s$ & $s$ & $\mathbf{s}$ & $s$ & $s$ & $s$ & $s$ & \multirow{3}{*}{ None } \\
\hline MP-6 & Blood Bank & & S. chonii & NEG & $\mathbf{R}$ & $s$ & $s$ & $\mathrm{~s}$ & $s$ & $\mathbf{R}$ & $s$ & $s$ & $s$ & $\mathbf{s}$ & $s$ & $s$ & $s$ & $\mathbf{R}$ & $s$ & \\
\hline MP-10 & Patho Lab & & S. arlettae & \multicolumn{16}{|c|}{ AST not available } & \\
\hline \multirow[t]{2}{*}{ MP-23 } & \multirow[t]{2}{*}{ Med Ward } & \multirow{13}{*}{ Non-HCW } & s. haemolyticus & POS & $\mathbf{R}$ & $\mathbf{R}$ & $\mathbf{R}$ & $\mathbf{R}$ & $\mathbf{R}$ & $\mathbf{R}$ & $\mathbf{R}$ & s & s & s & s & $\mathbf{R}$ & $s$ & $\mathbf{R}$ & $\mathbf{R}$ & $\begin{array}{l}\text { BETA- LACTAMS MODIFICATION OF } \\
\text { PBP(mecA) }\end{array}$ \\
\hline & & & A. otitis & \multicolumn{16}{|c|}{ AST not available } & None \\
\hline MP-24 & Med Ward & & S. haemolyticus & POS & $\mathbf{R}$ & $\mathbf{R}$ & $s$ & $\mathbf{R}$ & $\mathbf{R}$ & $\mathbf{R}$ & $\mathbf{R}$ & $s$ & s & $\mathbf{s}$ & s & $\mathbf{R}$ & s & $\mathbf{s}$ & $\mathbf{R}$ & $\begin{array}{l}\text { BETA- LACTAMS MODIFICATION OF } \\
\text { PBP(mecA) }\end{array}$ \\
\hline MP-28 & Med Ward & & S. cohnii & NEG & $\mathrm{s}$ & s & $\mathbf{s}$ & $\mathbf{R}$ & $\mathbf{R}$ & 1 & $s$ & $s$ & s & s & $\mathbf{s}$ & $\mathbf{R}$ & $s$ & $\mathbf{s}$ & s & None \\
\hline MP-29 & Med Ward & & S. haemolyticus & POS & $\mathbf{R}$ & $\mathbf{R}$ & $\mathbf{R}$ & R & $\mathbf{R}$ & $\mathbf{R}$ & $\mathbf{R}$ & $s$ & s & s & s & $\mathrm{s}$ & $s$ & $\mathbf{R}$ & $s$ & $\begin{array}{l}\text { BETA- LACTAMS MODIFICATION OF } \\
\text { PBP(mecA) }\end{array}$ \\
\hline \multirow{2}{*}{ MP-31 } & \multirow{2}{*}{ ENT Ward } & & S. warneri & NEG & $s$ & $\mathbf{s}$ & s & $\mathbf{s}$ & $s$ & $s$ & $s$ & $s$ & $s$ & s & s & s & s & s & $s$ & \multirow{4}{*}{ None } \\
\hline & & & S. hominis & NEG & $s$ & $s$ & $s$ & $s$ & $s$ & $s$ & $s$ & $s$ & $s$ & $s$ & $s$ & $s$ & $s$ & $s$ & $\mathbf{R}$ & \\
\hline MP-33 & ENT Ward & & S. saprophyticus & NEG & $\mathrm{R}$ & $\mathbf{s}$ & $\mathbf{s}$ & $\mathbf{s}$ & $s$ & $\mathbf{R}$ & $\mathbf{R}$ & $\mathrm{s}$ & $\mathrm{s}$ & $\mathrm{s}$ & $\mathrm{s}$ & $\mathrm{s}$ & 5 & $\mathrm{~s}$ & $s$ & \\
\hline MP-34 & ENT Ward & & S. warneri & NEG & $\mathbf{R}$ & $s$ & $s$ & $s$ & $s$ & $s$ & $s$ & $s$ & $s$ & $\mathrm{~s}$ & $s$ & $s$ & $s$ & $s$ & $s$ & \\
\hline MP-35 & ENT Ward & & s. haemolyticus & POS & R & $\mathbf{R}$ & s & $s$ & $s$ & $\mathbf{R}$ & $s$ & $s$ & s & s & $s$ & $\mathbf{R}$ & $s$ & s & $s$ & $\begin{array}{l}\text { BETA- LACTAMS MODIFICATION OF } \\
\text { PBP(mecA) }\end{array}$ \\
\hline \multirow{2}{*}{ MP-36 } & \multirow{2}{*}{ ENT Ward } & & S. saprophyticus & NEG & $\mathbf{R}$ & $s$ & $s$ & $s$ & $s$ & $\mathbf{R}$ & $\mathbf{R}$ & $s$ & $s$ & $s$ & $s$ & $\mathbf{R}$ & $s$ & $\mathrm{~s}$ & $\mathbf{s}$ & \multirow{3}{*}{ None } \\
\hline & & & K. kristinae & \multicolumn{16}{|c|}{ AST not available } & \\
\hline MP-40 & ENT Ward & & S. epidermidis & NEG & $\mathbf{R}$ & s & $\mathrm{s}$ & $\mathrm{s}$ & $s$ & $s$ & $\mathbf{R}$ & $s$ & $\mathrm{~s}$ & s & $\mathbf{s}$ & $\mathrm{s}$ & $\mathbf{s}$ & $\mathrm{s}$ & $\mathrm{s}$ & \\
\hline \multirow{2}{*}{ MP-39 } & \multirow{2}{*}{ ENT Ward } & \multirow{3}{*}{$\mathrm{HCW}$} & S. hominis & POS & $\mathbf{R}$ & $\mathbf{R}$ & $\mathbf{s}$ & $s$ & $s$ & $\mathbf{R}$ & $s$ & $\mathbf{s}$ & $\mathbf{s}$ & 1 & $s$ & $s$ & $s$ & s & $s$ & $\begin{array}{l}\text { BETA- LACTAMS MODIFICATION OF } \\
\text { PBP(mecA) }\end{array}$ \\
\hline & & & S. sciuri & NEG & $s$ & $s$ & $s$ & $s$ & $s$ & $s$ & $s$ & $s$ & s & $s$ & s & $\mathrm{s}$ & $s$ & s & s & \multirow{2}{*}{ None } \\
\hline MP-44 & $\mathrm{K}$ Ward & & S. xylosus & NEG & $\mathbf{R}$ & $s$ & $\mathrm{~s}$ & $s$ & $s$ & 1 & $s$ & $s$ & $\mathrm{~s}$ & $\mathrm{~s}$ & $\mathrm{~s}$ & $s$ & $s$ & $\mathrm{~s}$ & $s$ & \\
\hline MP-47 & Gyn Ward & Non-HCW & S. hominis & POS & $\mathbf{R}$ & $\mathbf{R}$ & $\mathbf{s}$ & $s$ & $s$ & $s$ & s & $\mathrm{s}$ & s & s & $\mathrm{s}$ & s & $s$ & s & s & $\begin{array}{l}\text { BETA- LACTAMS MODIFICATION OF } \\
\text { PBP(mecA) }\end{array}$ \\
\hline MP-53 & Gyn Ward & & S. epidermidis & NEG & $\mathrm{R}$ & $\mathbf{s}$ & $s$ & $s$ & $s$ & $\mathbf{R}$ & $s$ & $s$ & $s$ & $s$ & $\mathbf{s}$ & $s$ & $s$ & $s$ & $\mathbf{R}$ & None \\
\hline MP-64 & Gyn Ward & & E. rhushiopathiae & & & & & & & & ot av & lable & & & & & & & & \\
\hline MP-68 & Gyn Ward & & S. aureus & NEG & $\mathrm{R}$ & $s$ & $s$ & $s$ & $s$ & $\mathrm{R}$ & $s$ & $s$ & $s$ & $s$ & $s$ & $s$ & $s$ & $s$ & $s$ & \\
\hline MP-69 & Gyn Ward & & S. hominis & NEG & $\mathrm{s}$ & s & $\mathbf{s}$ & $s$ & $\mathrm{~s}$ & $s$ & 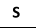 & $s$ & s & s & s & $\mathbf{s}$ & $\mathrm{s}$ & $\mathbf{s}$ & s & \\
\hline MP-72 & Gyn Ward & & S. hominis & NEG & $\mathbf{R}$ & $\mathbf{R}$ & $s$ & s & $s$ & $\mathbf{R}$ & $s$ & $s$ & s & s & s & R & $s$ & $\mathrm{~s}$ & $s$ & $\begin{array}{l}\text { BETA- LACTAMS MODIFICATION OF } \\
\text { PBP(mecA) }\end{array}$ \\
\hline MP-73 & Gyn Ward & & S. hominis & NEG & $\mathbf{R}$ & $\mathbf{s}$ & $s$ & $\mathbf{s}$ & $s$ & $\mathbf{R}$ & $s$ & $s$ & $s$ & s & $s$ & $s$ & $s$ & $\mathbf{s}$ & $s$ & \\
\hline MP-82 & Surg Ward & & Enterococcus spp. & NIL & $s$ & $s$ & $S(H L)$ & $s$ & s & $s$ & $\mathbf{R}$ & $s$ & $s$ & s & $s$ & s & $s$ & $s$ & $s$ & None \\
\hline MP-85 & Surg Ward & & S. epidermidis & POS & $\mathbf{R}$ & $\mathbf{R}$ & s & s & s & $\mathbf{R}$ & s & $s$ & s & s & s & s & $\mathrm{s}$ & s & $s$ & $\begin{array}{l}\text { BETA- LACTAMS MODIFICATION OF } \\
\text { PBP(mecA) }\end{array}$ \\
\hline
\end{tabular}

Fox Screen cefoxitin screen, Benzyl Pen benzylpenicillin, OXA oxacillin, GEN gentamicin, CIP ciprofloxacin, NVX levofloxacin, ERY erythromycin, CLI clindamycin, LZD linezolid, DAP daptomycin, TEC teicoplanin, VAN vancomycin, TET tetracycline, TGC tigecycline, RIF rifampicin, SXT trimethoprim/sulfamethoxazole. HL high level Gray highlight-mobile phones having growth of $>1$ organisms having the same gram reaction. Pink highlight-mobile phones having mixed growth of both Gram-positive and Gram-negative organisms

$S$ susceptible, $R$ resistant, POS positive, NEG negative 


\section{Antibiotic susceptibility testing}

For antibiotic susceptibility test (AST), the VITEK 2 system was used as per manufacturer's instructions. For GNB, N280 antibiotic cards which included a panel of 18 antibiotics were used (Table 3). Etrapenem was not included since it did not produce any results upon testing by VITEK 2. For GPC, P628 antibiotic cards with a panel of 16 antibiotics were used (Table 4). Cefoxitin was used as a surrogate marker for methicillin-resistant S. aureus. Rifampicin did not produce any results upon testing and thus excluded.

\section{Statistical analysis}

Data were analysed using Statistical Package for Social Sciences (SPSS) version 20. Odds ratio (OR) and confidence interval $(\mathrm{CI})$ were measured using logistic regression to analyse the factors associated with a possible source of contamination of mobile phones.

\section{Abbreviations}

AST: Antibiotic susceptibility testing; Cl: Class interval; CoNS: Coagulasenegative Staphylococci; ENT: Ears, nose and throat; ESBL: Extended spectrum beta-lactamases; GNB: Gram-negative bacilli; GPC: Gram-positive cocci; HCW: Health care worker; K ward: Substance abuse ward; MRSA: Methicillinresistant Staphylococcus aureus; Non-HCW: Non-health care worker; OR: Odds ratio; SPSS: Statistical Package for the Social Sciences

\section{Acknowledgements}

We are thankful to the staff and patients of Synod Hospital Aizawl, Mizoram, India, for their cooperation in sample collection during the study period.

\section{Authors' contributions}

CVS and PP were involved in sample collection and microbiological analysis. $\mathrm{SM}$ and $\mathrm{ZZ}$ were involved in the data analysis and interpretation of results. NSK, LN and RL have supervised and interpreted the reports of the research work. CVS, PP, ZZ and NSK drafted the manuscript. All authors read and approved the final manuscript.

\section{Funding}

The authors thank Advanced State Level Biotech Hub (BT/04/NE/2009) and Bioinformatics Infrastructural facility sponsored by Department of Biotechnology (DBT), New Delhi, Govt. of India for the financial support to carry out this work successfully.

\section{Availability of data and materials}

No datasets (culture deposits or sequence data) are generated and therefore are not applicable to this study.

\section{Ethics approval and consent to participate}

Ethical approval is not applicable in this study. However, verbal consent was obtained from all the study participants.

\section{Consent for publication}

Not applicable

\section{Competing interests}

The authors declare that they have no competing interests.

\section{Author details}

'Department of Biotechnology, Mizoram University, Aizawl, Mizoram 796004, India. ${ }^{2}$ Department of Microbiology, Synod Hospital, Durtlang, Aizawl, Mizoram 796025, India. ${ }^{3}$ Department of Pathology, Synod Hospital, Durtlang, Aizawl, Mizoram 796025, India.
Received: 19 August 2019 Accepted: 2 December 2019

Published online: 11 December 2019

\section{References}

1. Pal S, Juyal D, Adekhandi S, Sharma M, Prakash R, Sharma N, et al. Mobile phones: reservoirs for the transmission of nosocomial pathogens. Adv Biomed Res. 2015:4:144.

2. Loyola S, Gutierrez LR, Horna G, Petersen K, Agapito J, Osada J, et al. Extended-spectrum $\beta$-lactamase-producing Enterobacteriaceae in cell phones of health care workers from Peruvian pediatric and neonatal intensive care units. Am J Infect Control. 2016:44(8):910-6.

3. Kramer A, Schwebke I, Kampf G. How long do nosocomial pathogens persist on inanimate surfaces? A systemic review. BMC Infect Dis. 2006; 6(1):130.

4. Bell V, Ferraro J, Pimentel L, Pintado M, Fernandes T. One health, fermented foods, and gut microbiota. Foods. 2018;7(12):195.

5. Meadow JF, Altrichter AE, Green JL. Mobile phones carry the personal microbiome of their owners. Peer J. 2014;2:e447.

6. Ulger F, Esen S, Dilek A, Yanik K, Gunaydin M, Leblebicioglu H. Are we aware how contaminated our mobile phones with nosocomial pathogens? Ann Clin Microbiol Antimicrob. 2009;8(1):7.

7. Bobat R, Archary M, Lawler M, Mawlana S, Naidoo KL, Maphumulo S, et al. The presence and spectrum of bacteria colonizing mobile phones of staff and caregivers in high disease burden pediatric and neonatal wards in an urban teaching hospital in Durban, South Africa. South Afr J Infect Dis. 2017; 32(1):9-11.

8. Anderson A. Evaluation of microbial contamination in frequently used fomites in Kuwait. Biodivers Int J. 2017:1(1):80-6.

9. Szczuka E, Jablonska L, Kaznowski A. Coagulase-negative staphylococci: pathogenesis, occurrence of antibiotic resistance genes and in vitro effects of antimicrobial agents on biofilm-growing bacteria. J Med Microbiol. 2016; 65:1405-13.

10. Kumar BV, Hobanu YH, Abdulhaq A, Jerah AA, Hakami OM, Eltigani M, et al. Prevalence of antibacterial resistant bacterial contaminants from mobile phones of hospital inpatients. Libyan J Med. 2014;9(1):25451.

11. Rodloff AC, Goldstein EJC, Torres A. Two decades of imipenem therapy. J Antimicrob Chemother. 2006:58(5):916-29.

12. Torumkuney D, Papaparaskevas J, Morrissey I. Results from the Survey of Antibiotic Resistance (SOAR) 2014-16 in Greece. J Antimicrob Chemother. 2018;73:v36-42

13. Joly-Guillou ML, Kempf M, Cavallo JD, Chomarat M, Dubreuil L, Maugein J, et al. Comparative in vitro activity of meropenem, imipenem and piperacillin/tazobactam against 1071 clinical isolates using 2 different methods: a French multicenter study. BMC Infect Dis. 2010;10(1):1-9.

14. Alder A, Ginadkowski M, Baraniak A, Izdebski R, Fiett J, Hryniewicz W, et al. Transmission dynamics of ESBL-producing Escherichia coli clones in rehabilitation wards at a tertiary care centre. Clin Microbiol Infect. 2012; 18(12):E497-505.

15. Hadir ELK. Microbial contamination of mobile phones in the medical laboratory technology department of a private university in Alexandria, Egypt. Int J Curr Microbiol App Sci. 2017;6(6):200-11.

16. Bhavnani SM, Ambrose PG, Craig WA, Dudley MN, Jones RN. Outcomes evaluation of patients with ESBL- and non-ESBL-producing Escherichia coli and Klebsiella species as defined by CLSI reference methods: report from the SENTRY antimicrobial surveillance program. Diagn Microbiol Infect Dis. 2006;54(3):231-6.

17. Osaka University. Threat of 'nightmare bacteria' with resistance to last-resort antibiotic colistin 2018. https://medicalxpress.com/news/2018-12-threatnightmare-bacteria-resistance-last-resort.html

18. Otto M. Virulence factors of the coagulase-negative staphylococci. Front Biosci. 2004;9:841-63.

19. Rhode H, Mack D, Christner M, Burdelskia C, Frankea G, Knobloch JK-M. Pathogenesis of staphylococcal device-related infections: from basic science to new diagnostic, therapeutic and prophylactic approaches. Rev Med Microbiol. 2006;17(2):45-54.

20. Nathwani D, Wood MJ. Penicillins: a current review of their clinical pharmacology and therapeutic use. Drugs. 1993;45(6):866-94.

21. Tagoe DN, Gyande VK, Ansah EO. Bacterial contamination of mobile phones: when your mobile phone could transmit more than just a call. WebmedCentral Microbiology. 2011. https://doi.org/10.9754/journal.wmc. 2011.002294. 
22. Vazquez-Guillamet $\mathrm{C}$, Kollef MH. Treatment of gram-positive infections in critically ill patients. BMC Infect Dis. 2014;14(1):1-8.

23. Mamtora D, Saseedharan S, Bhalekar P, Katakdhond S. Microbiological profile and antibiotic susceptibility pattern of Gram-positive isolates at a tertiary care hospital. J Lab Physicians. 2019;11:144-8.

24. Allegranzi B, Pittet D. Role of hand hygiene in healthcare-associated infection prevention. J Hosp Infect. 2009;73(4):305-15.

25. Koscova J, Hurnikova Z, Pistl J. Degree of bacterial contamination of mobile phone and computer keyboard surfaces and efficacy of disinfection with chlorhexidine digluconate and triclosan to its reduction. Int J Environ Res Public Health. 2018;15(10):2238.

26. Ngonda F. Assessment of bacterial contamination of toilets and bathroom doors handle/knobs at Daeyang Luke hospital. Pharm Biol Eval. 2017;4(4):193-7.

27. Roy P, Ahmed NH, Biswal I, Grover RK. Multidrug-resistant Staphylococcus hominis subsp. novobiosepticus causing septicemia in patients with malignancy. Indian J Pathol Microbiol. 2014;57(2):275-7.

28. Chu YW, Leung CM, Ts H, Ng KC, Leung CB, Leung HY, et al. Skin carriage of Acinetobacters in Hong Kong. J Clin Microbiol. 1999;37(9):2962-7.

29. Berlau J, Aucken H, Malnick H, Pitt T. Distribution of Acinetobacter species on skin of healthy humans. Eur J Clin Microbiol Infect Dis. 1999;18(3):179-83.

30. Seifert H, Dijkshoorn L, Gerner-Smidt P, Pelzer N, Tjernberg I, Vaneechoutte M. Distribution of Acinetobacter species on human skin: comparison of phenotypic and genotypic identification methods. J Clin Microbiol. 1997; 35(11):2819-25.

31. Howard A, O'Donoghue M, Feeney A, Sleator RD. Acinetobacter baumanii: an emerging opportunistic pathogen. Virulence. 2012;3(3):243-50.

32. Peleg AY, Seifert H, Paterson DL. Acinetobacter baumanii: emergence of a successful pathogen. Clin Microbiol Rev. 2008;21(3):538-82.

33. Zaman RMQ, Helmi NRM. Isolation of bacteria from mobile phones before and after decontamination: study carried out at King Abdulaziz University, Jeddah, Saudi Arabia. Afr J Microbiol Res. 2017;11(35):1371-8.

34. Chelliah A, Ravinder T, Katragadda R, Leela KV, Babu RN. Isolation of MRSA ESBL and AmpC- $\beta$-lactamases from neonatal sepsis at a tertiary care hospital. J Clin Diagn Res. 2014;8(6):24-7.

35. Morubagal RR, Shivappa SG, Mahale RP, Neelambike SM. Study of bacterial flora associated with mobile phones of healthcare workers and nonhealthcare workers. Iran J Microbiol. 2017;9(3):143-51.

36. Koroglu M, Gunal S, Yildiz F, Savas M, Ozer A, Altindis M. Comparison of keypads and touch-screen mobile phones/devices as potential risk for microbial contamination. J Infect Dev Ctries. 2015;9(12):1308-14.

37. Joyanes P, Conejo MDC, Martinez-Martinez L, Perea EJ. Evaluation of the VITEK 2 system for the identification and susceptibility testing of three species of nonfermenting gram-negative rods frequently isolated from clinical samples. J Clin Microbiol. 2001;39(9):3247-53.

\section{Publisher's Note}

Springer Nature remains neutral with regard to jurisdictional claims in published maps and institutional affiliations.

Ready to submit your research? Choose BMC and benefit from:

- fast, convenient online submission

- thorough peer review by experienced researchers in your field

- rapid publication on acceptance

- support for research data, including large and complex data types

- gold Open Access which fosters wider collaboration and increased citations

- maximum visibility for your research: over $100 \mathrm{M}$ website views per year

At BMC, research is always in progress.

Learn more biomedcentral.com/submissions 